\title{
Advanced Electrocatalytic Performance of Activated Carbon Prepared from Asphalt
}

\author{
Huiying Wang ${ }^{1,2}$, Peifeng Cheng ${ }^{1,2, *}$ and Yiqi Wang ${ }^{1,2}$ \\ ${ }^{1}$ College of Civil Engineering, Northeast Forestry University, Harbin City, Heilongjiang \\ Province, 150000, P.R. China \\ ${ }^{2}$ School of Civil Engineering and Civil Engineering, Heilongjiang Institute of Technology, Harbin \\ City, Heilongjiang Province, 150000, P.R. China \\ *E-mail: peifengcheng@tom.com
}

doi: $10.20964 / 2018.04 .12$

Received: 4 December 2017 / Accepted: 29 January 2018 / Published: 6 March 2018

In the present work, nitric and sulfuric acids were used for the chemical conversion of asphalt to activated carbon (AC) powder. An extremely high cation exchange capacity was obtained under the following conditions: no airflow rate injection and ratio of acid/asphalt, $30 \mathrm{wt} \%$. When the $\mathrm{pH}$ was $c a$. 3 (initial $\mathrm{pH}$ range of 3 to 10), a stable zero point of charge was observed for the obtained product. The final composites showed the following integrated advantages: the effectiveness of the oxygen reduction reaction (ORR) active sites and the excellence of the electrical conductivity. The final material can be used not only as an effective metal-free electrode material but also as a competitive substitute material for the recently discovered $\mathrm{Pt} / \mathrm{C}$ catalyst given the remarkable electrochemical activity toward ORR observed under alkaline conditions.

Keywords: Asphalt; Activated carbon; Ion exchange; Oxygen reduction reaction; Chemical activation

\section{$\underline{\text { FULL TEXT }}$}

(C) 2018 The Authors. Published by ESG (www.electrochemsci.org). This article is an open access article distributed under the terms and conditions of the Creative Commons Attribution license (http://creativecommons.org/licenses/by/4.0/). 